\title{
Sublethal Effects of Chronic Exposure to an Organochlorine Compound on Northern Leopard Frog (Rana pipiens) Tadpoles
}

\author{
Karen A. Glennemeier, Robert J. Denver \\ Department of Biology, University of Michigan, Ann Arbor, Michigan 48109
}

Received 30 August 2000; revised 20 February 2001; accepted 28 March 2001

\begin{abstract}
Global contamination with organochlorine compounds (OCs) has posed developmental and reproductive problems in wildlife worldwide. However, little is known about the impact of OCs or other pollutants on amphibians, despite mounting concerns about amphibian population declines and developmental deformities in the wild. Wildlife populations may be affected critically by sublethal impacts of anthropogenic disturbances, yet little research has focused on such effects in amphibians. In the current study, northern leopard frog (Rana pipiens) tadpoles were chronically exposed to a polychlorinated biphenyl (PCB) congener, 77-TCB, and effects on behavior, morphology, competitive performance, and corticosterone content were determined. $R$. pipiens activity levels and feeding rates were decreased by 77-TCB exposure, but morphology of mouthparts and body proportions were unaffected. 77-TCB enhanced growth and altered competitive interactions between R. pipiens and wood frog (Rana sylvatica) tadpoles. $R$. pipiens tadpoles exposed to 77-TCB showed decreased whole-body corticosterone content compared to controls both before and after injection with adrenocorticotropic hormone (ACTH). All of the factors examined in the current study play critical roles in tadpole development, growth, survivorship, and eventual reproductive success, suggesting negative population-level consequences for amphibians in PCB-contaminated habitats. (c) 2001 by John Wiley \& Sons, Inc. Environ Toxicol 16: 287-297, 2001
\end{abstract}

Keywords: organochlorine; PCB; polychlorinated biphenyl; amphibian; Rana pipiens; endocrine disruptor; corticosterone; behavior; competition

\section{INTRODUCTION}

Environmental contamination with organochlorine (OC) compounds has become a global problem, with negative consequences for human and wildlife health

Correspondence to: Robert J. Denver; e-mail: rdenver@umich.edu. Contract grant sponsors: Office of the Great Lakes, Michigan Great Lakes Protection Fund; University of Michigan, Department of Biology and Rackham School of Graduate Studies.

Contract grant sponsor: NSF.

Contract grant number: IBN 9974672. becoming increasingly evident. Although the use of polychlorinated biphenyls (PCBs) in developed countries was phased out in the late 1970s, these compounds persist at high levels in the environment. Atmospheric transport of PCBs has contributed to their global distribution, with measurable concentrations found in wildlife from such remote locations as the Canadian Arctic (Birge et al., 1978; Eisler, 1986).

Organochlorine compounds, including PCBs, dichlorodiphenyltrichloroethane (DDT), other pesticides, and dioxin, accumulate in wildlife tissues and are associated 
with developmental and reproductive problems in birds, fish, mammals, reptiles, and invertebrates (birds: Elliot et al., 1996; Gilbertson et al., 1991; Hart et al., 1991; Kubiek et al., 1989; Weseloh et al., 1983; Wiemeyer et al., 1984); (fish: Leatherland, 1992; Walker et al., 1994); (mammals: Fanelli et al., 1980); (reptiles: deSolla et al., 1998; Guillette et al., 1994); (invertebrates: Depinto et al., 1993). Early observations of thinned eggshells and reproductive failure among Great Lakes birds exposed to OC compounds prompted research into the effects of these compounds on the gonadal steroids estrogen and testosterone (Lincer and Peakall, 1970; Risebrough et al., 1968). Since then, alterations of reproductive hormone axes have been demonstrated in virtually all vertebrate classes exposed to OC compounds, although the specific effects differ with taxon and with particular OC compound (cf. Crews et al., 1994; Guillette et al., 1994; Kleeman et al., 1990; Machala et al., 1998; Nesaretnam et al., 1996; Nowicki and Norman, 1972).

OC compounds also have been found to impact the thyroid and adrenal axes. Such disruptions have the potential to alter basic developmental processes, as the hormones produced by these two axes play critical roles in morphogenesis. As with the gonadal hormones, the nature of these alterations varies with taxon, OC compound, and study (cf. corticosteroids: Byrne et al., 1988; Fowles et al., 1997; Freeman and Sangalang, 1977; Jonsson et al., 1993; Lund, 1994; Miller et al., 1993); (thyroid hormones: Lans et al., 1993; Leatherland and Sonstegard, 1978; Rickenbacher et al., 1986; Van den Berg et al., 1994). Several studies have demonstrated that exposure to OCs alters an animal's corticosteroid response to an external stressor or an adrenocorticotropic hormone (ACTH) injection (Gendron et al., 1997; Hontela et al., 1992, 1995; Ilan and Yaron, 1983; Quabius et al., 1997).

Most of these studies have included birds, fishes, and mammals. Many fewer studies have examined the effects of PCBs on reptiles or amphibians (see deSolla et al., 1998; Guillette et al., 1994, for reptile studies). The few amphibian studies that have been conducted report variable effects of OC contamination, including decreased survival, growth, and swimming speed in ranid frog eggs (Jung and Walker, 1997; Rosenshield et al. 1999), impaired corticosteroid response to stress in mudpuppies (Gendron et al., 1997), and reversed sex ratios in cricket frogs (Reeder et al., 1998), but also findings of no effect in adult ranid frogs from OC-contaminated orchards (Harris et al., 1998a, 1998b) or amphibian assemblages in PCB-contaminated habitats (Fontenot et al., 1996). Gutleb et al. (1999) exposed gravid adult female Xenopus laevis and Rana tempo- raria frogs to OCs and found developmental malformations and impaired growth in their eggs and tadpoles.

Amphibians are drawing increasing attention from conservation biologists, due to reports of widespread declines in amphibian populations (Crump et al., 1992; Wake, 1991; Wyman, 1990) and a high incidence of deformities in populations of the upper Midwest (EPA, 1996; Ouellet et al., 1997). These problems have highlighted the fact that we know very little about the sensitivity of amphibians to various types of environmental disturbance, including pollution. We also know little about natural patterns of population size fluctuation or background rates of developmental deformities.

The present study examined the effects on amphibian fitness components of a PCB congener, 3,3',4,4'tetrachlorobiphenyl (77-TCB), that has known endocrine, developmental, and toxic effects in other taxa (Darnerud et al., 1996; Nesaretnam et al., 1996; Poland and Knutson, 1982; Van den Berg et al., 1988). 77-TCB (hereafter TCB) is one of many PCB congeners found in contaminated Michigan wetlands (Glennemeier and Begnoche, in press). The northern leopard frog, Rana pipiens, is native to the Midwest, and its numbers have been reported to be declining (Lannoo et al., 1994; Orr et al., 1998). While it is unlikely that PCB contamination is the most important explanation for reported $R$. pipiens declines (Orr et al., 1998), knowledge of the potential impacts of PCBs on this species will be essential to amphibian conservation efforts, given the global and persistent nature of PCB contamination.

Direct effects of pollution on survivorship are well documented and vary with taxon and pollutant (cf. Birge et al., 1978; Birge and Cassidy, 1983; Mahaney, 1994). The potential for sublethal effects of pollutants is now being recognized as well; for example, the reproductive and developmental effects of OCs discussed above. Tadpole behavior and morphology strongly influence growth and survivorship (Anholt and Werner, 1995; Hoff et al., 1999; Relyea and Werner, 1999; Skelly and Werner, 1990; Skelly, 1992; Werner, 1991), but few studies have examined the effects of pollution or disturbance on these traits.

The current study examined the effects of chronic exposure to TCB on behavior, morphology, and competitive performance in $R$. pipiens tadpoles. We also analyzed TCB effects on basal and ACTH-stimulated whole-body corticosterone content, since the interrenal axis is known to influence animal behavior, growth, and development. By using an integrative approach, we hoped to examine emergent effects at higher organizational levels that would not be predicted by knowledge of biochemical or behavioral mechanisms alone. 


\section{MATERIALS AND METHODS}

\section{Animal Husbandry and Treatment}

Rana pipiens eggs were obtained from laboratory populations at Nasco Science (Fort Atkinson, WI), and $R$. sylvatica eggs were collected from ponds within the Pinckney Recreation Area in Livingston Co., Michigan. Later analysis of tadpoles revealed nondetectable TCB levels. Tadpoles were maintained in environmental chambers at $22 \pm 2^{\circ} \mathrm{C}$, at $12 \mathrm{~L}: 12 \mathrm{D}$, and all experiments were conducted under these environmental conditions. For all experiments, each treatment was randomly assigned a position on each of four shelves within the environmental chamber. Tadpoles were fed a 3:1 mixture of ground Purina Rabbit Chow: Tetramin Fish Flakes. Food level was $10 \%$ of tadpole body mass per day unless otherwise noted for an individual experiment. Tadpoles were weighed approximately weekly, and food levels were adjusted according to tadpoles' increased mass.

\section{Effect of Vehicle on Corticosterone Content}

TCB (3,3',4,4' -tetrachlorobiphenyl; $99+\%$ pure; Ultra Scientific, Inc., Kingstown, RI) exposure was achieved by dissolving the compound in an acetone solution, adding this solution to the tadpoles' ground food, and allowing the solution to evaporate in a fume hood. Prior to experiments with TCB, potential vehicle effects were determined by comparing growth and corticosterone content of tadpoles fed food treated with $100 \%$ acetone, a $1 \%$ acetone solution, or no acetone (unsoaked). At Gosner stage 25, tadpoles were placed into 4-L plastic tanks at a density of 10 per tank, with three replicate tanks per treatment. After 33 days of feeding on acetone-treated or control food, animals were anesthetized in $0.01 \%$ benzocaine, weighed, and frozen at $-20^{\circ} \mathrm{C}$ for later analysis of whole-body corticosterone content. For all experiments in which tadpoles were collected for corticosterone analyses, animals were anesthetized by immersion in $0.01 \%$ benzocaine immediately upon entry of the investigator into the environmental chamber to minimize any stress response of the animals to the presence of the investigator.

\section{Behavior and Morphology}

Beginning at Gosner stage 25, tadpoles were fed food containing either 10,100 , or $1000 \mathrm{ng} / \mathrm{g}$ (ppb) TCB, with 10 animals per 4 -L plastic tank and 6 replicate tanks per treatment. Due to effects of the pure acetone vehicle (see Results), TCB was dissolved in a $1 \%$ acetone solution before addition to the food and drying in a fume hood. Behavioral observations were conducted after 5, 9, 14, and 16 days of TCB exposure. Observations were made by the investigator standing next to the tanks and recording the number of tadpoles in each tank swimming, resting, and feeding at a given moment. After all tanks had been observed once, the procedure was repeated immediately for a total of 10 observations per tank per day. Tank labels were not visible to the investigator during observations.

Data were recorded as the proportion of the total number of animals in a tank doing each activity. The 10 observations of each tank in a given day were averaged to provide the mean value for that tank on that day. These means were then used to calculate a treatment mean and standard error among the six replicate tanks for each treatment, giving a sample size of 6 (not 60) for statistical analyses. The 10 observations were conducted to provide an accurate estimate of the activity within a tank and were not considered separate replicates in a statistical sense.

On day 17, ten tadpoles per treatment were sampled randomly from the 6 replicate tanks and preserved in $10 \%$ formalin for morphological measurements. Tail length and depth, tail muscle depth, and body mass were measured using a stereo microscope and camera, with Bioscan Optimas image analysis software (Optimas Corp., Bothell, WA). Gross morphology of mouthparts was qualitatively assessed.

\section{Competitive Performance}

Given the behavioral effects of TCB exposure (see Results), $R$. pipiens and $R$. sylvatica tadpoles were experimentally manipulated to determine whether TCB exposure affected the competitive relationship between the species or the growth of each species alone. All experiments were initiated at Gosner stage 25-26 (Gosner, 1960) and conducted in 4-L plastic tanks, with 5 replicate tanks per treatment. Tadpoles were fed food containing $1000 \mathrm{ng} / \mathrm{g}$ (ppb) TCB or $1 \%$ acetone vehicle, at a food level of $7.5 \%$ of body mass per day. This food level has previously been shown to induce resource competition among these species (Werner, 1992). Tanks included either $6 R$. pipiens, $12 R$. sylvatica, or 6 $R$. pipiens plus $12 R$. sylvatica tadpoles. Per capita food levels were held constant among all treatments, so that effects of density could be isolated from any effects of decreased individual food rations. However, this means that absolute food levels were greater in higher-density tanks. $R$. sylvatica tadpoles were added in greater numbers in the two-species tanks because we wanted to 
reduce $R$. pipiens intraspecific-relative to interspecific-competition. Doing so allowed us to determine effects of the heterospecific competitor ( $R$. sylvatica) on the target species ( $R$. pipiens) with fewer confounding effects of conspecific competitors (see Underwood, 1986).

After 7 days' treatment, animals were weighed and relative growth calculated by subtracting a tank's mean initial mass for a species from the tank's mean final mass and dividing this difference by the tank's mean initial mass for that species. Measures of relative growth for replicate tanks were averaged to provide an overall mean relative growth for the treatment. Competitive response was defined as a species' relative growth in the presence of heterospecific competitors (using the mean of the three replicate tanks) divided by its relative growth in single-species tanks (mean of three replicate tanks). The variance of each quotient was estimated using the variances of the respective means for that quotient (see Kish, 1965, for formula). Values greater than 1 indicate that a species grew better in the presence of competitors than when alone, and values less than 1 indicate poorer growth in the presence of competitors.

\section{Corticosterone Content and Response to ACTH}

Whole-body corticosterone content after ACTH injection was measured in TCB-exposed $R$. pipiens tadpoles. Tadpoles were fed food containing either 10 , 100 , or $1000 \mathrm{ng} / \mathrm{g}$ (ppb) TCB beginning at Gosner stage 25 (Gosner, 1960), with 10 animals per 4-L plastic tank and 3 replicates per treatment.

After 28 days of treatment, all tadpoles from the three tanks within a treatment were combined into a single tank and then randomly assigned to uninjected, vehicle (saline)-injected, or ACTH-injected groups. Each group from each treatment was placed into a separate 4-L tank, undisturbed and unfed for $24 \mathrm{hr}$ prior to injection. Tadpoles in the ACTH treatment group were injected through the tail muscle into the dorsal peritoneum with 0.2 IU ACTH (Sigma-Aldrich, St. Louis, MO) per gram body mass, delivered in $10 \mu \mathrm{L}$ phosphate buffered saline (PBS; $0.02 \mathrm{M}, \mathrm{pH}$ 7.2). Tadpole mass ranged from 50 to $150 \mathrm{mg}$. Vehicle-injected tadpoles were injected with PBS alone. Five hours after injection, tadpoles were anesthetized by immersion in $0.01 \%$ benzocaine, weighed, and frozen at $-20^{\circ} \mathrm{C}$ for later analysis of whole-body corticosterone. Uninjected tadpoles also were collected to determine basal corticosterone content. All animals were collected between 1500 and $1700 \mathrm{hr}$, to minimize any circadian variation in corticosterone content.

\section{Corticosterone Extraction and Radioimmunoassay}

Whole-body corticosterone content was determined by radioimmunoassay (RIA) following organic extraction of the hormone from collected tadpoles. The extraction procedure is described by Hayes and $\mathrm{Wu}$ (1995) and Denver (1998). Briefly, tissues were homogenized in ethyl acetate and the extracts fractionated by thin layer chromatography (TLC) to separate corticosterone from other lipids. The region of the TLC lane containing the corticosterone (as determined by calibration with both radiolabeled and radioinert corticosterone; see Denver, 1998) was scraped and the silica collected into a borosilicate glass tube. The silica was extracted with ethyl ether, and the extract was dried under nitrogen and resuspended in PBS-gelatin (PBS-G; $0.02 \mathrm{M}, \mathrm{pH}$ 7.3) for corticosterone RIA. The RIA was conducted as described by Licht et al. (1983). Anticorticosterone serum was purchased from Endocrine Sciences (Calabasas, CA) and $\left[{ }^{3} \mathrm{H}\right]$-corticosterone from NEN Life Science Products, Inc. (Boston, MA). Samples from a single experiment were analyzed in a single RIA or in multiple RIAs on a single day. Inter- and intraassay coefficients of variation were 13 and $8 \%$, respectively, and were monitored by including a quality control standard (pooled rat plasma) in each RIA.

\section{Statistics}

Vehicle effect data were analyzed using one-way ANOVA of treatment versus body mass or corticosterone content of individual tadpoles, followed by Fisher's least squares difference (LSD) pairwise comparisons between individual groups. For determinations of statistical significance using LSD comparisons, alpha values were adjusted to account for multiple comparisons.

Behavioral data were analyzed by repeated-measures ANOVA of treatment versus proportion resting or feeding (proportions were square root arcsine transformed), repeated for the four observation dates. Linear regression of the logarithm of TCB dose versus proportion time (square root arcsine transformed) was used to analyze data within individual observation dates. The morphological ratios of body mass-to-tail length, body mass-to-tail depth, and body mass-to-tail muscle depth for each tadpole were analyzed using MANOVA of treatment versus the three ratios. Linear regressions of body mass versus tail length, tail depth, and tail muscle depth demonstrated linear relationships between body mass and each variable $\left(R^{2}>0.93\right.$; $p<0.00005)$.

For competition experiments, the effect of TCB exposure on growth in the absence of competitors was 
analyzed using two-way ANOVA, with relative growth as the dependent variable and TCB treatment and species as independent variables. The competitive hierarchy between species (i.e., the relative growth of each species in the presence of the other) was analyzed using Student's $t$-test, with species as the independent variable and relative growth as the dependent variable. Since competitive response was estimated using the means shown in Table I, ANOVA could not be performed $(n=1)$. The estimated variances associated with the competitive response ratios provide a qualitative assessment of treatment effect.

For corticosterone content after ACTH injection, data were analyzed using two-way ANOVA, with corticosterone content of individual tadpoles as the dependent variable and TCB dose and ACTH manipulation as independent variables. Fisher's LSD pairwise comparisons were performed to determine differences between specific treatment groups, using adjusted alpha values to account for multiple comparisons.

\section{RESULTS}

\section{Effect of Vehicle on Corticosterone Content}

Whole-body corticosterone content of tadpoles fed $100 \%$ acetone-treated food was approximately one-half that of tadpoles fed untreated food or $1 \%$ acetonetreated food (Fig. $1 ; F_{2,27}=3.72 ; p=0.035$ ). Body mass did not differ among treatment groups (data not shown). Because of the vehicle effect on corticosterone content, subsequent experiments utilized the $1 \%$ acetone solution as a vehicle control. This amount of acetone was sufficient to maintain the $77-\mathrm{TCB}$ in solution prior to adding it to the food.

Acetone has been shown to negatively affect mortality, growth, and behavior in amphibians and other

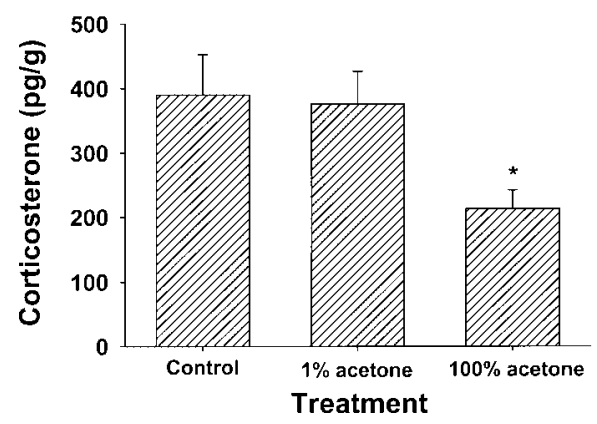

Fig. 1. Whole-body corticosterone content of $R$. pipiens tadpoles fed food that had been soaked in acetone or $1 \%$ acetone. Error bars represent standard errors of the mean $(n=10)$. Asterisk $(*)$ indicates significantly different from control group (LSD, $p=0.02$ ). The $1 \%$ acetone group did not differ from the control (LSD, $p=0.84$ ).

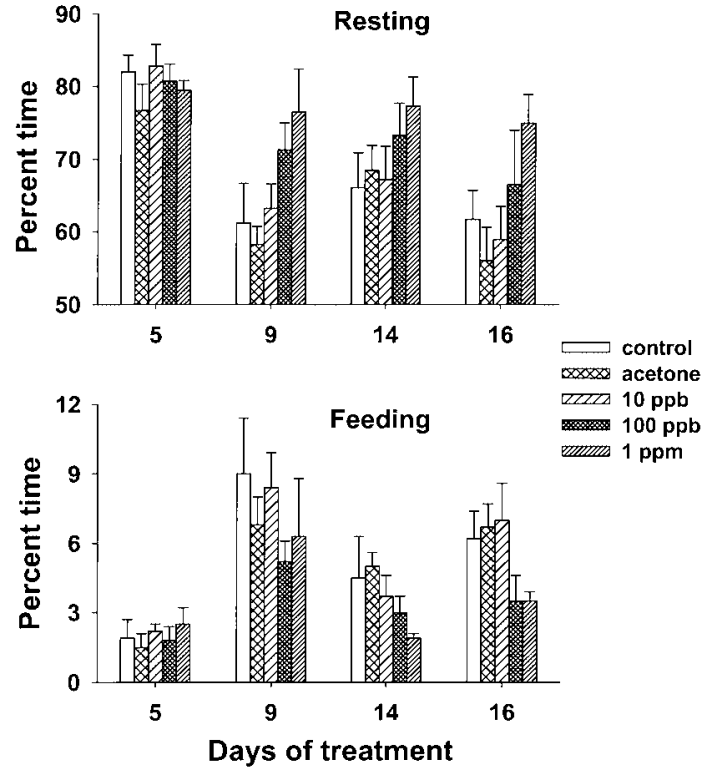

Fig. 2. Percent time resting or feeding by $R$. pipiens tadpoles fed food containing 77 -TCB for $5,9,14$, and 16 days. Treatment with 77-TCB began at Gosner stage 25. Error bars represent standard errors of the mean of six replicate tanks (see Materials and Methods).

animals (Semlitsch et al., 1995; Tunc et al., 1997). The current results suggest that even the residues remaining after evaporation are sufficient to affect tadpole physiology (Fig. 1). Although no effects on growth were seen in the current study, we have previously noted positive effects of acetone residues on $R$. pipiens growth and negative effects on mortality (unpublished data). Many studies utilize acetone, ethanol, or other solvents as vehicles for toxin or drug administration without testing directly for the effects of these solvents on their experimental systems, an omission which could lead to misinterpretation of results.

\section{Behavior and Morphology}

Tadpoles exposed to TCB showed decreased activity and foraging behavior compared with controls (Fig. 2). No differences in resting or feeding time were found between control and acetone-control groups on any observation date; so these groups were combined for all analyses.

Repeated-measures ANOVA of proportion of time spent resting showed significant main effects of treatment $\left(F_{4,25}=4.98 ; p=0.007\right)$ and observation date $\left(F_{3,75}=13.6 ; p<0.0005\right)$, with no significant interaction between the two $\left(F_{12,75}=1.29 ; p=0.26\right)$. The significant date effect reflects the general decrease in time spent resting after the first observation date. TCB 
treatment did not affect resting behavior on the first observation date but did at each date thereafter (see statistics for individual dates, below).

Repeated-measures ANOVA of proportion of time spent feeding showed a marginally nonsignificant main effect of treatment $\left(F_{4,25}=2.53 ; p=0.079\right)$, a significant effect of observation date $\left(F_{3,75}=18.68 ; p<\right.$ $0.0005)$, and no significant interaction between the two $\left(F_{12,75}=1.15 ; p=0.34\right)$. Time spent feeding differed among observation dates but did not consistently increase or decrease across the four observation dates. TCB treatment affected feeding time in the two latter but not the first two observation dates.

Within individual observation dates, resting time significantly increased with increased TCB dose after 9, 14 , and 16 days of exposure $(p=0.001,0.037,0.011$, respectively). TCB exposure did not affect resting time after only 5 days of exposure $(p=0.98)$. Feeding time decreased with increased TCB dose after 14 and 16 days of exposure ( $p=0.016,0.012$, respectively). TCB exposure did not affect feeding time after 5 or 9 days' exposure ( $p=0.24,0.17$, respectively).

No significant differences in morphological ratios were detected among treatment groups (MANOVA mass:tail fin length $F_{4,45}=0.10, p=0.98$; mass:tail fin depth $F_{4,45}=0.32, p=0.86$; mass:tail muscle depth $F_{4,45}=0.37, p=0.83$; data not shown). Mouthparts also showed no gross, qualitative differences among groups. Tadpoles from all groups possessed intact, keratinized mouthparts and a full complement of tooth rows.

\section{Competitive Performance}

Table I shows the relative growth of $R$. pipiens and $R$. sylvatica tadpoles in single-species tanks and in tanks with competitors, in control and TCB treatments. Mean masses $( \pm$ SEM $)$ at the start of competition experiments were $92 \pm 7 \mathrm{mg}$ for $R$. pipiens and $68 \pm 3 \mathrm{mg}$ for $R$. sylvatica. In the absence of competition, both species grew more when fed TCB-treated food than control food, with $R$. sylvatica showing a greater response to

TABLE I. Relative growth of tadpoles in single-species tanks and in tanks with competitors, fed control food, or food treated with TCB ${ }^{a}$

\begin{tabular}{llcc}
\hline & \multicolumn{2}{c}{ Treatment } \\
\cline { 3 - 4 } & & Control & TCB \\
\hline R. pipiens & Alone & $0.6 \pm 0.05$ & $1.0 \pm 0.06$ \\
& With competitor & $1.1 \pm 0.1$ & $0.9 \pm 0.1$ \\
R. sylvatica & Alone & $0.7 \pm 0.09$ & $2.2 \pm 0.5$ \\
& With competitor & $1.6 \pm 0.09$ & $1.1 \pm 0.1$ \\
\hline
\end{tabular}

\footnotetext{
${ }^{a}$ Values represent the means of three replicate tanks, plus-orminus the standard error of the mean.
}

TCB than $R$. pipiens (Table I; treatment $F_{1,16}=15.7$, $p=0.001 ;$ species $F_{1,16}=7.2, p=0.016$; interaction $\left.F_{1,16}=5.5, p=0.033\right)$. Tadpoles of both species fed control food exhibited greater growth in the presence of heterospecific competitors than when reared alone, but $R$. sylvatica tadpoles grew better than their $R$. pipiens competitors (Table $\mathrm{I} ; t=3.2, p=0.013$ ). The competitive responses of both species were dramatically reduced when tadpoles were fed TCB-treated food (Table I and Fig. 3). Furthermore, the performance difference between the two species was not seen with TCB-treated food (Table I; $t=1.6, p=0.16$ ); i.e., $R$. sylvatica competitive response was reduced by feeding TCB to a larger extent than that of $R$. pipiens (Fig. 3).

\section{Corticosterone Content and Response to ACTH}

Tadpoles treated with 100 or 1000 ppb TCB showed decreased corticosterone content when undisturbed (basal content) and after ACTH injection compared with controls (Fig. 4). Two-way ANOVA showed significant main effects of TCB dose $\left(F_{4,105}=4.09 ; p=0.004\right)$ and ACTH manipulation $\left(F_{2,105}=28.91 ; p<0.0005\right)$ and a significant interaction between the two $\left(F_{8,105}=\right.$ 4.57; $p<0.0005)$.

Pairwise comparison of basal corticosterone content among all TCB treatments showed a significant de-

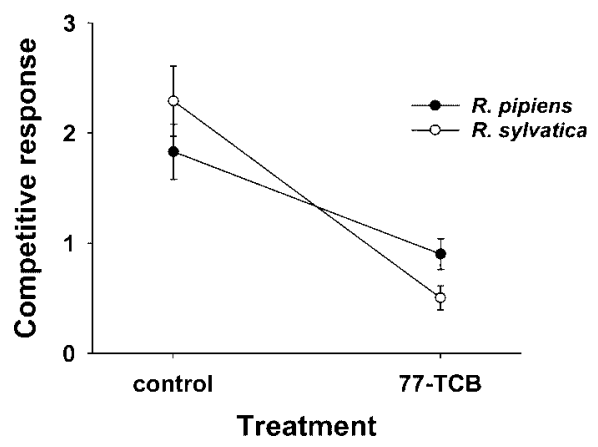

Fig. 3. Competitive response of $R$. pipiens and $R$. sylvatica tadpoles when both were fed food containing 77-TCB or $1 \%$ acetone. Competitive response is defined as a species' relative growth in the presence of heterospecific competitors (using the mean of the three replicate tanks) divided by its relative growth in single-species tanks (mean of three replicate tanks; see Materials and Methods). Values greater than 1 indicate better performance in the presence of competitors than in single-species tanks. Values less than 1 indicate poorer performance in the presence of competitors. Single-species $R$. pipiens density was 6 per 4-L tank; $R$. sylvatica density was 12 per 4-L tank. Competition tanks contained 6 R. pipiens and 12 R. sylvatica tadpoles. Error bars were estimated as described in Kish (1965). 
crease in the 100-ppb TCB group and the 1000-ppb TCB group compared to controls, using $\alpha=0.0125$ $(p=0.0003,0.0078$, respectively). No differences in corticosterone content existed among the acetone, control, and 10-ppb TCB groups.

Comparison of corticosterone content of ACTH-injected tadpoles among all TCB treatments showed a significant decrease in the 10,100 , and $1000 \mathrm{ppb}$ TCB groups compared to controls, using $\alpha=0.0125$ ( $p=$ $0.010,0.0006,0.0027$, respectively). The acetone group and the control group did not differ significantly.

Saline injection increased corticosterone content above basal values only in the $100-p p b$ TCB group $(p<0.0005)$. Within the control, acetone, 100-ppb TCB, and 1000-ppb TCB doses, ACTH injection resulted in significantly increased corticosterone content over basal levels $(p<0.0005,<0.0005,=0.008$, and $<0.0005$, respectively). ACTH injection resulted in a nonsignificant corticosterone increase in the 10-ppb TCB group, using a corrected $\alpha$ of $0.01(p=0.025)$. Comparing ACTH injection to saline injection within each treatment group revealed significant increases in corticosterone content in the control and 1000-ppb TCB groups $(p<0.0005,=0.009$, respectively $)$, and marginally nonsignificant increases in the acetone group and 10-ppb TCB groups, using a corrected $\alpha$ of 0.01 ( $p=0.037,0.046$, respectively).

Both basal corticosterone content and corticosterone content after ACTH injection decreased with increased TCB dose. The response to ACTH was superimposed on an endogenous stress response, although the response to saline injection was significant in only one group. The ratio of ACTH-injected to basal

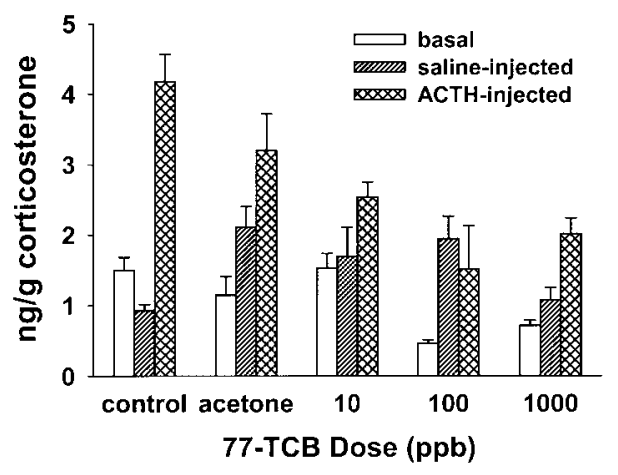

Fig. 4. Whole-body corticosterone content of $R$. pipiens tadpoles fed food containing 77-TCB for 28 days, followed by injection with 0.2 IU ACTH or saline. Animals were collected $5 \mathrm{hr}$ after injection for analysis of whole-body corticosterone. Uninjected animals were collected at the same time as injected animals for determination of basal corticosterone content. Error bars represent standard errors of the mean of eight individual tadpoles. corticosterone content was similar among all groups (see Fig. 4).

\section{DISCUSSION}

This study is the first to examine the sublethal effects of chronic, controlled PCB exposure on larval amphibians. 77-TCB decreased activity and foraging behavior, altered competitive interactions, and decreased corticosterone content in $R$. pipiens tadpoles. These results suggest that PCB contamination has the potential to negatively affect amphibian populations at multiple organizational levels.

\section{Behavior and Morphology}

$R$. pipiens tadpoles exposed to TCB spent more time resting and less time feeding than unexposed tadpoles. Behavior profoundly influences tadpole growth and mortality, often mediated through effects on species interactions (Anholt and Werner, 1995; Relyea and Werner, 1999; Skelly and Werner, 1990; Skelly, 1992; Werner, 1991). The population-level impacts of pollution's effects on behavior could therefore be significant. Other studies have reported behavioral effects of pollution on amphibians and other taxa. Jung and Jagoe (1995) found slower swimming speeds and higher predation susceptibility in hylid tadpoles exposed to low $\mathrm{pH}$ and high aluminum levels characteristic of environments impacted by acid rain. Lefcort et al. (1998) found decreased predator avoidance behavior in metal-exposed ranid tadpoles, and Cooke (1971) found increased predation by newts on DDT-treated tadpoles, due to changes in tadpole behavior that increased newt detection rates. Several additional studies have demonstrated behavioral effects of exposure to pollution in various taxa (Berrill et al. 1993; Boyd et al., 1990; Bridges, 1997, 1999; Dodson and Hanazato, 1995; Doving, 1991; Rosenshield et al., 1999; Semlitsch et al., 1995). Our study adds to the growing body of evidence demonstrating that pollution may negatively impact wildlife populations through sublethal, behavioral effects.

\section{Competitive Performance}

Lower activity and feeding rates often decrease competitive performance in tadpoles, as more active competitors remove available resources from the water (cf. Morin and Johnson, 1988; Skelly, 1992; Werner, 1992). We examined the effects of TCB exposure on the competitive interaction between $R$. pipiens and $R$. sylvatica tadpoles to distinguish effects at this higher organizational level. 
The presence of resource competitors influences individual fitness, either directly through inadequate resource intake or indirectly through effects of the interaction on other larval attributes. Increased competition intensity has been shown to decrease larval size, growth rate, survivorship, length of the larval period, and size at metamorphosis (Brockelman, 1969; Smith, 1987; Wilbur and Collins, 1973; Wilbur, 1977). Both a longer larval period and a smaller size at metamorphosis can delay adult reproductive maturity, decrease size at first reproduction, and in some cases decrease adult survival to first reproduction (Berven and Gill, 1983; Semlitsch et al., 1988; Smith, 1987). Decreased growth rate and longer time to metamorphosis also may increase exposure time to aquatic predators (Werner, 1986; Wilbur, 1980) or decrease the chance of metamorphosing before a quickly drying pond disappears (Newman, 1992). Despite the importance of competition for individual fitness, few studies have examined the interaction between pollution and species interactions in any taxon (see Cooke, 1971; Jung and Jagoe, 1995; Kiesecker, 1996; Warner et al., 1993).

In this study we exposed both $R$. pipiens and $R$. sylvatica to TCB simultaneously and then measured the effect of the pollutant on interspecific competition. An alternative design would be to treat the "target" species with a pollutant while placing it in competition with an unexposed competitor. However, the mode of administration of the TCB (in the food) prohibited such a design. The design used here precluded any inferences about mechanism but presumably reflected the natural condition more accurately than would single-species exposure. In a natural system it is unlikely that one species would be exposed to a contaminant while another was not exposed, especially for two species with such similar larval life histories as $R$. pipiens and $R$. sylvatica that are known to occur in the same ponds (Werner and Glennemeier, 1999).

We found that both species grew more in the presence of competitors than when alone (see Table I and Fig. 3). Increased growth in the presence of competitors has been observed previously in laboratory studies (Werner, 1992) and is likely an artifact of the increased overall food levels in the competition tanks compared to single-species tanks. More food is available for consumption, although per capita levels are the same. Thus, if foraging efficiency increases or if tadpoles are more active in the presence of competitors (cf. Anholt and Werner, 1995), there will be greater overall resource consumption and more opportunity for growth, provided these gains outweigh the metabolic costs of the increased activity.

The response of each species to competition changed in the presence of TCB. Since TCB decreased activity in $R$. pipiens tadpoles (Fig. 2), this species, when TCB- exposed, may have been unable to increase activity or foraging efficiency to take advantage of elevated food levels in the competition tanks. Behavioral effects of TCB on $R$. sylvatica tadpoles are unknown, although this species showed a greater TCB-exposed reduction in competitive performance than that of $R$. pipiens. These data suggest an interaction between TCB exposure and competitor presence that could alter predictions about competitive outcomes in polluted environments, as both species may be affected more negatively by competition in polluted habitats than in unpolluted habitats.

When competition was present, $R$. sylvatica tadpoles were competitively superior (i.e., showed greater relative growth) to $R$. pipiens tadpoles, but this relationship changed when both competitors were exposed to TCB (Table I). These results suggest that TCB contamination in nature could potentially affect anuran community composition. For example, if competition intensity were low, growth of $R$. sylvatica would be more strongly enhanced by TCB than that of $R$. pipiens (as we observed a surprising TCB enhancement of growth in single-species treatments; see Table I). These differences could be reflected in metamorphic size and timing, both of which have important effects on fitness (see above). If competition intensity were high, TCB exposure would diminish the competitive superiority of $R$. sylvatica over $R$. pipiens, which could affect community composition and would likely affect individual fitness in the two species.

Knowledge of the effect of TCB on $R$. sylvatica behavior and morphology would help to identify the mechanisms responsible for the altered competitive relationship and response observed between TCB-exposed $R$. pipiens and $R$. sylvatica tadpoles. Furthermore, experiments in field enclosures would help determine the extent to which the tadpoles' performance in the laboratory reflects that in the natural habitat.

The decrease in basal whole-body corticosterone content caused by exposure to TCB might explain, in part, the increased growth observed in noncompeting TCB-exposed tadpoles (Table I), as corticosteroids are known to be growth inhibitory in most vertebrates (see Chester Jones and Henderson, 1976). Chronic exposure to high levels of exogenous corticosterone depresses growth in tadpoles (Hayes et al., 1993; Hayes and Wu, 1995). Decreased corticosterone levels would thus be expected to enhance growth, although this hypothesis has not been tested directly. Simultaneous treatment with TCB and exogenous corticosterone (hormone replacement) might clarify the role of corticosterone changes in mediating the growth effects of TCB exposure. 


\section{Corticosterone Content and Response to ACTH}

Corticosteroids are known to influence animal behavior (cf. DeNardo and Sinervo, 1994; Moore and Zoeller, 1985; Silverin, 1986; Wingfield et al., 1997), and we hypothesized that one site for TCB's disruption of tadpole behavior is on the hypothalamo-pituitary-interrenal (HPI) axis. Interference with the HPI (adrenal) axis could impair normal tadpole development, as the corticosteroids and corticotropin releasing hormone (CRH) are known to accelerate amphibian metamorphosis (Denver, 1993, 1996; Hayes, 1995; Kikuyama et al., 1993). These hormones also are important mediators of the developmental response to changes in the environment such as pond drying (Denver, 1997, 1998). Furthermore, alterations in this endocrine axis could increase an animal's susceptibility to disease or environmental stressors (Carey, 1993). Despite the importance of the corticosteroids in amphibians, no studies have examined effects of chronic, controlled OC exposure on corticosteroid production in these animals.

Importantly, the TCB doses used in the present study are much lower than those used in many PCB exposure studies and fall within the range of total PCBs found in sediments from contaminated wetlands in the Midwest (from nondetectable to $39 \mathrm{ppm}$ dry weight in southwest Michigan; Glennemeier and Begnoche, in press). Several studies have found that low doses of heavy metals, OC compounds, other pollutants, and exogenous hormones have stronger effects than high doses on some physiological and behavioral variables (Darbre et al., 1984; Davis and Svendsgaard, 1990; Freeman et al., 1984; Reddell and Sutherland, 1984; Vom Saal et al., 1997). Studies that focus solely on high pollutant doses would benefit from extending their dose ranges 100- to 1000-fold lower, as low doses may produce effects that cannot be predicted by simple extrapolation from effects seen at higher doses.

We found that chronic exposure to TCB depressed basal whole-body corticosterone content. Possible sites for this depression are steroid hormone biosynthesis or metabolism. OCs are known to affect the conversion of cholesterol to pregnenalone, the rate-limiting step in steroid hormone synthesis (Kagawa and Waterman, 1995; Kleeman et al., 1990; Machala et al., 1998; Moore et al., 1991). While no studies have directly examined OC effects on steroid hormone synthesis or metabolism in amphibians, these animals should respond similarly to OC exposure as other vertebrates since steroid biosynthetic pathways are conserved among vertebrates (Sandor et al., 1976).

Whole-body corticosterone content also could be decreased through actions at higher regulatory centers, such as downregulation of corticotropin releasing hormone (CRH) or ACTH secretion if TCB were acting as a glucocorticoid receptor agonist. Interrenal tissue damage also could be responsible for decreased steroid synthesis, as other studies have reported adrenal or interrenal damage in wildlife exposed to pollutants (Banerjee and Bhattacharya, 1994; Jonsson et al., 1993; Norris et al., 1997); (but see Gendron et al., 1997). Interference of OCs with the enzymes responsible for steroid hormone synthesis or degradation seems the most likely explanation for the current results, given the strong evidence for such effects in other animals.

Regardless of the mechanism by which TCB alters corticosterone content in $R$. pipiens tadpoles, a question arises from the current results as to the potential impact on $R$. pipiens populations of such an alteration. The developmental actions of corticosteroids are well known (see above), but almost nothing is known about the role of corticosteroids in tadpole ecology or what constitutes a natural "stressor." We are currently examining the consequences of small changes in corticosterone for $R$. pipiens fitness, determining the role of corticosterone in mediating tadpoles' responses to environmental change, and identifying natural stressors in the environment that activate this endocrine axis.

The current results suggest that TCB exposure could significantly impact amphibian individual- and population-level fitness through effects at multiple organizational levels. This impact may be especially pronounced in disturbed environments where the response to stressors or habitat changes could be critical to population viability. Elucidation of the endocrine stress axis' role in mediating such responses will help to predict the long-term consequences of exposure to compounds that interfere with corticosterone and this endocrine axis.

We wish to thank Lia Florey, Charlyn Primous, Luis Schiesari, Greg Schneider, and Kerry Yurowicz for help with various aspects of animal care, experiments, and data analysis. The University of Michigan Museum of Zoology and Department of Biology provided physical support and animal care facilities. Dr. Earl Werner provided valuable comments on the research and manuscript.

\section{REFERENCES}

Anholt, B. R.; Werner, E. E. Ecology 1995, 76, 2230-2234.

Banerjee, S.; Bhattacharya, S. Ecotoxicol Environ Safety 1994, 29, 265-275.

Berrill, M.; Bertram, S.; Wilson, A.; Louis, S.; Brigham, D.; Stromberg, C. Environ Toxicol Chem 1993, 12, 525-539.

Berven, K. A.; Gill, D. E. Am Zool 1983, 23, 85-97.

Birge, W. J.; Cassidy, R. A. Fundam Appl Toxicol 1983, 3, 359-368. 
Birge, W. J.; Black, J. A.; Westerman, A. G. Water Resources Research Institute Report, University of Kentucky, Lexington, KY, 1978, No. 118.

Boyd, C. A.; Weiler, M. H.; Porter, W. P. J Toxicol Environ Health 1990, 30, 209-221.

Bridges, C. M. Environ Toxicol Chem 1997, 16, 1935-1939.

Bridges, C. M. J Herpetol 1999, 33, 303-306.

Brockelman, W. Y. Ecology 1969, 50, 632-644.

Byrne, J. J.; Carbone, J. P.; Pepe, M. G. Arch Environ Contam Toxicol 1988, 17, 47-54.

Carey, C. Conserv Biol 1993, 7, 355-362.

Chester Jones, I.; Henderson, I. W. General, Comparative and Clinical Endocrinology of the Adrenal Cortex; Academic Press: New York/London, 1976.

Cooke, A. S. Nature 1971, 229, 275-276.

Crews, D.; Bergeron, J. M.; Bull, J. J.; Flores, D.; Tousignant, A.; Skipper, J. K.; Wibbels, T. Dev Genet 1994, 15, 297-312.

Crump, M. L.; Hensley, F. R.; Clark, K. L. Copeia 1992, 1992, 413-420.

Darbre, P. D.; Curtis, S.; King, R. J. B. Cancer Res 1984, 44, 2790-2793.

Darnerud, P. O.; Morse, D.; Klasson-Wehler, E.; Brouwer, A. Toxicology 1996, 106, 105-114.

Davis, J. M.; Svendsgaard, D. J. J Toxicol Environ Health 1990, 30, 71-83.

DeNardo, D. F.; Sinervo, B. Horm Behav 1994, 28, 273-287.

Denver, R. J. Gen Comp Endocrinol 1993, 91, 38-51.

Denver, R. J. In Metamorphosis: Postembryonic Reprogramming of Gene Expression in Amphibian and Insect Cells; Gilbert, L. I.; Tata, J. R.; Atkinson, B. G., Eds.; Academic Press: San Diego, CA, 1996; pp 434-464.

Denver, R. J. Horm Behav 1997, 31, 169-179.

Denver, R. J. Gen Comp Endocrinol 1998, 110, 326-336.

Depinto, L. M.; Coull, B. C.; Chandler, G. T. Environ Toxicol Chem 1993, 12, 1909-1918.

deSolla, S. R.; Bishop, C. A.; Van Der Kraak, G.; Brooks, R. J. Environ Health Perspect 1998, 106, 253-260.

Dodson, S. I.; Hanazato, T. Environ Health Perspect 1995, 103, 7-11.

Doving, K. B. Comp Biochem Physiol C 1991, 100, 247-252.

Eisler, R. US Fish and Wildlife Service Biological Report 1986, 85(1.7), $72 \mathrm{pp}$.

Elliot, J. E.; Norstrom, R. J.; Smith, G. E. J. Arch Environ Contam Toxicol 1996, 31, 354-367.

EPA. Deformed Great Lakes frogs prompt EPA consideration of research, Water Policy Report, 1996.

Fanelli, R.; Bertoni, M. P.; Bonfanti, M.; Castelli, M. G.; Chiabrando, C.; Martelli, G. P.; Noe, M. A.; Noseda, A.; Garattini, S.; Binaghi, C.; Marazza, V.; Pezza, F.; Pozzoli, D.; Cigognetti, G. Arch Environ Contam Toxicol 1980, 9, 569-577.

Fontenot, L. W.; Noblet, G. P.; Platt, S. G. J Elisha Mitchell Scientific Society 1996, 112, 20-30.

Fowles, J. R.; Fairbrother, A.; Trust, K. A.; Kerkvliet, N. I. Environ Res 1997, 75, 119-129.
Freeman, H. C.; Sangalang, G. B. Arch Environ Contam Toxicol 1977, 5, 369-383.

Freeman, H. C.; Sangalang, G. B.; Uthe, J. F. In Contaminant Effects on Fisheries; Cairns, C. W.; Hodson, P. V.; Nriagu, J. O., Eds.; Wiley: New York, 1984; Vol. 16, pp 197-211.

Gendron, A. D.; Bishop, C. A.; Fortin, R.; Hontela, A. Environ Toxicol Chem 1997, 16, 1694-1706.

Gilbertson, M.; Kubiak, T. J.; Ludwig, J. P.; Fox, G. J Toxicol Environ Health 1991, 33, 455-520.

Glennemeier, K. A.; Begnoche, L. J. J Herpetol, in press.

Gosner, K. L. Herpetologica 1960, 16, 183-190.

Guillette, Jr., L. J.; Gross, T. S.; Masson, G. R.; Matter, J. M.; Percival, H. F.; Woodward, A. R. Environ Health Perspect 1994, 102, 680-688.

Gutleb, A. C.; Appelman, J.; Bronkhorst, M. C.; van den Berg, J. H. J.; Spenkelink, A.; Brouwer, A.; Murk, A. J. Environ Toxicol Pharmacol 1999, 8, 1-14.

Harris, M. L.; Bishop, C. A.; Struger, J.; Ripley, B.; Bogart, J. P. Environ Toxicol Chem 1998a, 17, 1351-1363.

Harris, M. L.; Bishop, C. A.; Struger, J.; van den Heuvel, M. R.; Van Der Kraak, G.; Dixon, D. G.; Ripley, B.; Bogart, J. P. Environ Toxicol Chem 1998b, 17, 1338-1350.

Hart, L. E.; Cheng, K.; Whitehead, W. E.; Shah, R. M.; Lewis, R. J.; Ruschkowski, S. R.; Blair, R. W.; Bennett, D. C.; Bandiera, S. M.; Norstrom, R. J.; Bellward, G. D. J Toxicol Environ Health 1991, 32, 331-344.

Hayes, T. B. J Exp Zool 1995, 271, 95-102.

Hayes, T. B.; Wu, T. H. J Exp Zool 1995, 271, 103-111.

Hayes, T. B.; Chan, R.; Licht, P. J Exp Zool 1993, 266, 206-215.

Hoff, K. v.; Blaustein, A. R.; McDiarmid, R. W.; Altig, R. In Tadpoles: The Biology of Anuran Larvae; McDiarmid, R. W.; Altig, R., Eds.; The University of Chicago Press: Chicago, 1999; pp 215-239.

Hontela, A.; Rasmussen, J. B.; Audet, C.; Chevalier, G. Arch Environ Contam Toxicol 1992, 22, 278-283.

Hontela, A.; Dumont, P.; Duclos, D.; Fortin, R. Environ Toxicol Chem 1995, 14, 725-731.

Ilan, Z.; Yaron, Z. J Fish Biol 1983, 22, 657-669.

Jonsson, C. J.; Lund, B. O.; Brandt, I. Ecotoxicology 1993, 2, 41-53.

Jung, R. E.; Jagoe, C. H. Can J Zool 1995, 73, 2171-2183.

Jung, R. E.; Walker, M. K. Environ Toxicol Chem 1997, 16, 230-240.

Kagawa, N.; Waterman, M. R. In Cytochrome P450: Structure, Mechanism, and Biochemistry; Ortiz de Montellano, P. R., Eds.; Plenum Press: New York, 1995; pp 419-442.

Kiesecker, J. Ecol Appl 1996, 6, 1325-1331.

Kikuyama, S.; Kawamura, K.; Tanaka, S.; Yamamoto, K. Int Rev Cytol 1993, 145, 105-148.

Kish, L. Survey Sampling. Wiley Press: New York, 1965; p 192.

Kleeman, J. M.; Moore, R. W.; Peterson, R. E. Toxicol Appl Pharmacol 1990, 106, 112-125. 
Kubiek, T. J.; Harris, H. J.; Smith, L. M.; Schwartz, T. R.; Stalling, T. R.; Trick, J. A.; Sileo, L.; Docherty, D. E.; Erdman, T. C. Arch Environ Contam Toxicol 1989, 18, 706-727.

Lannoo, M. J.; Lang, K.; Waltz, T.; Phillips, G. S. Am Midl Nat 1994, 131, 311-319.

Lans, M. C.; Klasson-Wehler, E.; Willemsen, M.; Meussen, E.; Safe, S.; Brouwer, A. Chem-Biol Interact 1993, 88, $7-21$.

Leatherland, J. F.; Sonstegard, R. A. J Fish Res Board Can 1978, 35, 1285-1289.

Leatherland, J. F. In Chemically-Induced Alterations in Sexual and Functional Development: The Wildlife/Human Connection; Colborn, T.; Clement, C., Eds.; Princeton Scientific: Princeton, NJ, 1992; pp 129-146.

Lefcort, H.; Meguire, R. A.; Wilson, L. H.; Ettinger, W. F. Arch Environ Contam Toxicol 1998, 35, 447-456.

Licht, P.; McCreery, B. R.; Barnes, R.; Pang, R. Gen Comp Endocrinol 1983, 50, 124-145.

Lincer, J. L.; Peakall, D. B. Nature 1970, 228, 783.

Lund, B. O. Environ Toxicol Chem 1994, 13, 911-917.

Machala, M.; Neca, J.; Drabek, P.; Ulrich, R.; Sabatova, V.; Nezveda, K.; Raszyk, J.; Gajduskova, V. Comp Biochem Physiol A 1998, 120, 65-70.

Mahaney, P. A. Environ Toxicol 1994, 13, 259-265.

Miller, D. B.; Gray, J., E.; Andrews, J. E.; Luebke, R. W.; Smialowicz, R. J. Toxicology 1993, 81, 217-222.

Moore, F. L.; Zoeller, R. T. Gen Comp Endocrinol 1985, 60, 252-258.

Moore, R. W.; Jefcoate, C. R.; Peterson, R. E. Toxicol Appl Pharmacol 1991, 109, 85-97.

Morin, P. J.; Johnson, E. A. Oikos 1988, 53, 398-407.

Nesaretnam, K.; Corcoran, D.; Dils, R. R.; Darbre, P. Mol Endocrinol 1996, 10, 923-936.

Newman, R. A. Bioscience 1992, 42, 671-678.

Norris, D. O.; Felt, S. B.; Woodling, J. D.; Dores, R. M. Gen Comp Endocrinol 1997, 108, 343-351.

Nowicki, H. G.; Norman, A. W. Steroids 1972, 19, 85-99.

Orr, L.; Neumann, J.; Vogt, E.; Collier, A. In Status and Conservation of Midwestern Amphibians; Lannoo, M. J., Ed.; University of Iowa Press: Iowa City, 1998; pp 91-93.

Ouellet, M.; Bonin, J.; Rodrigue, J.; DesGranges, J.; Laire, S. J Wildl Dis 1997, 33, 95-104.

Poland, A.; Knutson, J. C. Annu Rev Pharmac Toxicol 1982, 22, 517-554.

Quabius, E. S.; Balm, P. H. M.; Bonga, S. E. W. Gen Comp Endocrinol 1997, 108, 472-482.

Reddell, R. R.; Sutherland, R. L. Eur J Cancer Clin Oncol 1984, 20, 1419-1424.

Reeder, A. L.; Foley, G. L.; Nichols, D. K.; Hansen, L. G.; Wikoff, B.; Faeh, S.; Eisold, J.; Wheeler, M. B.; Warner, R.; Murphy, J. E.; Beasley, V. R. Environ Health Perspect 1998, 106, 261-266.

Relyea, R. A.; Werner, E. E. Ecology 1999, 80, 2117-2124.

Rickenbacher, U.; McKinney, J. D.; Oatley, S. J.; Blake, C. C. F. J Med Chem 1986, 29, 641-648.
Risebrough, R. W.; Rieche, P.; Peakall, D. B.; Herman, S. G.; Kirven, M. N. Nature 1968, 220, 1098-1102.

Rosenshield, M. L.; Jofré, M. B.; Karasov, W. H. Environ Toxicol Chem 1999, 18, 2478-2486.

Sandor, T.; Fazekas, A. G.; Robinson, B. H. In General, Comparative and Clinical Endocrinology of the Adrenal Cortex; Chester Jones, I.; Henderson, I. W., Eds.; Academic Press: New York/London, 1976; 25-142.

Semlitsch, R. D.; Scott, D. E.; Pechmann, J. H. K. Ecology 1988, 69, 184-192.

Semlitsch, R. D.; Foglia, M.; Mueller, A.; Steiner, I.; Fioramonti, E.; Fent, K. Environ Toxicol Chem 1995, 14, 1419-1423.

Silverin, B. Gen Comp Endocrinol 1986, 64, 67-74.

Skelly, D. K. Ecology 1992, 73, 704-708.

Skelly, D. K.; Werner, E. E. Ecology 1990, 71, 2313-2322.

Smith, H. M. Ecology 1987, 68, 344-350.

Tunc, I.; Erler, F.; Dagli, F.; Calis, O. J Stored Prod Res 1997, 33, 181-185.

Underwood, A. J. In Community Ecology: Pattern and Process; Kikkawa, J.; Anderson, D. J., Eds.; Blackwell: London, England, 1986; pp 240-268.

Van den Berg, K. J.; Zurcher, C.; Brouwer, A. Toxicol Lett 1988, 41, 77-86.

Van den Berg, M.; Craane, B. L. H. J.; Sinnige, T.; vanMonrik, S.; Dirksen, S.; Boudewijn, T.; van der Gaag, M.; Lutke-Schipholt, I. J.; Spenkelink, B.; Brouwer, A. Environ Toxicol Chem 1994, 13, 803-816.

Vom Saal, F. S.; Timms, B. G.; Montano, M. M.; Palanza, P.; Thayer, K. A.; Nagel, S. C.; Dhar, M. D.; Ganjam, V. K.; Parmigiani, S.; Welshons, W. V. Proc Natl Acad Sci 1997, 94, 2056-2061.

Wake, D. B. Science 1991, 253, 860.

Walker, M. K.; Cook, P. M.; Batterman, A. R.; Butterworth, B. C.; Berini, C.; Libal, J. J.; Hufnagle, L. C.; Peterson, R. E. Can J Fish Aquat Sci 1994, 51, 1410-1419.

Warner, S. C.; Travis, J.; Dunson, W. A. Ecology 1993, 74, 183-194.

Werner, E. E. Am Nat 1986, 128, 319-341.

Werner, E. E. Ecology 1991, 72, 1709-1720.

Werner, E. E. Copeia 1992, 1992, 26-35.

Werner, E. E.; Glennemeier, K. Copeia 1999, 1999, 1-12.

Weseloh, D. V.; Teeple, S. M.; Gilbertson, M. Can J Zool 1983, 61, 427-436.

Wiemeyer, S. N.; Lamont, T. G.; Bunck, C. M.; Sindelar, C. R.; Gramlich, F. J.; Fraser, J. D.; Byrd, M. A. Arch Environ Contam Toxicol 1984, 13, 529-549.

Wilbur, H. M. Ecology 1977, 58, 196-200.

Wilbur, H. M. Annu Rev Ecol Syst 1980, 11, 67-93.

Wilbur, H. M.; Collins, J. P. Science 1973, 182, 1305-1314.

Wingfield, J. C.; Hunt, K.; Breuner, C.; Dunlap, K.; Fowler, G. S.; Freed, L.; Lepson, J. In Behavioral Approaches to Conservation in the Wild; Clemmons, J. R.; Buchholz, R., Eds.; Cambridge University Press: Cambridge, 1997; pp 95-131.

Wyman, R. L. Conserv Biol 1990, 4, 350-352. 